\title{
Hematocolpo em Imperfuração Himenial e suas consequências: Relato de caso
}

\author{
Hematometrocolpos in Imperforate Hymen and its consequences: Case report
}

Carolina Rohr Elmôr Coutinho Miguel ${ }^{\dagger *}$, Camila Rohr Coutinho Elmôr Miguel „José Raphael Bigonha Ruffato

Como citar esse artigo. Miguel,

CRC; Miguel, CRCE; Ruffato,

JRB; Hematocolpo em Imperfuração Himenial e suas consequências: Relato de caso. Revista de Saúde. 2018 Jul./Dez.; 09 (2): 27-30.

\begin{abstract}
Resumo
Hematometrocolpo é a retenção de sangue na região uterina e no canal vaginal devido ao bloqueio do corrimento ginecológico, sendohímen imperfurado (HI) umas de suas causas.O HI é perceptível em qualquer período de vida pelo exame físico do aparelho genital externo, sendo notadofrequentemente durante a puberdade,quando surgem sintomas acarretados pela obstrução. Desta forma, o objetivo deste trabalho foi relatar o casode uma adolescente com caracteres sexuais secundários adequados para a idade,em estágios M3/P3 de Tanner, ausência de sexarca e menarca, a qualmanifestou clínica de abdômen agudo secundário aohematocolpo pelaimperfuração himenial.
\end{abstract}

Palavras-chave: Dor abdominal secundária; Hematocolpo; Hímen imperfurado.

\begin{abstract}
Hematometrocolposistheretentionofblood in theuterusand vagina, duetotheblockage ofthegynecological discharge, beingtheimperforatehymen (HI) oneof its causes. HI isnoticeableatany age over physicalexaminationoftheexternal genital tract. However, beingnoticeablemostofthe time duringpuberty, theappearanceofsymptomscausedbythe obstruction. Thus, theobjectiveofthisreportisto present anadolescent, withsecondarysexual characteristicssuitable for age, in stages M3 / P3 ofTanner, absenceofmenarche and sexual activity, whichshowedacute abdomen clinicas a consequenceofhematocolpusbyimperforatehymen.

Keywords: Secondary abdominal pain; Hematocolpus; Imperforatehymen.
\end{abstract}

\section{Introdução}

Hidrometrocolpos é a retenção dosfluidos na região uterina e região vaginal, em associação a obstrução dosistema genital. Quando existe acumulação de sangue, esta retenção é denominadahematometrocolpos ${ }^{1}$.Esses líquidos acumuladossão decorrentes de situaçõescom obstrução, como membrana vaginal, atresia vaginal ehímen imperfurado(HI) ${ }^{2}$.

Esse fato ocorre, frequentemente, no nascimento ou na puberdade. Na fase puberal, o hematometrocolpos pode ocasionar distensão da região vaginal, uterina e trompas pelosangue ${ }^{1}$.

A razão mais frequente de hidrometrocolpos é a imperfuração himenial, fato este detectados desde a década de $40^{3}$.A partir do seio urogenital origina-se o hímen, sendo sua imperfuração adotada como erro de desenvolvimento, excluindo outras deformaçõescongênitas ${ }^{4}$.A porcentagem de acometimento é entre $0,05 \%$ a $0,1 \%$ com nascimento em tempo gestacional adequado ${ }^{5}$.Há história familiar de imperfuraçãohimenial,mas, frequentemente, seu acometimento é isolado ${ }^{5}$. Existem diversas causas de máformação do sistema genital, tais como atresias vaginais associadas, comumente, a alterações no sistema urinário, polidactilia e regiãoanalimperfurada ${ }^{6}$.

A menarca faz parte do desenvolvimento puberal, sendo um processo tardio. Éprevistoque maior parte das crianças e adolescentes tenhamalcançadoa maturação sexual em estágio M3/P3 de Tanner até aprimeiramenstruação ${ }^{7}$ Apresenta-se sinal clínico essencial de HI ao observar divergência no desenvolvimento puberal em estágio avançado e semmenarca ${ }^{7}$.

Ossintomas mais comuns de hímen imperfurado são dor abdominal/pélvica cíclica, dor lombar, retenção urinária por vezes complicada com uretrohidronefrose em meninas supostamente na fase pré-menarca ${ }^{7}$.

Ainspeção do sistema genital externo é

Afiliação dos autores: † Discente do Curso de Medicina, Universidade de Vassouras, RJ

\$ Discente do Curso de Medicina, Universidade Federal de Juiz de Fora, MG

$\S$ Docente do Curso de Medicina, Universidade de Vassouras, RJ

* Email de correpondência: carol.rohr1@gmail.com 
fundamentalpara detectar tal alteração em adolescentes com clínica de abdômen agudo em atendimentos de urgência. Tal procedimento, evitaque o diagnóstico sejaimperceptível, tardio ou errôneo, bem como evita condutas e procedimentos desnecessários, além de maior risco de morbidade relacionada ${ }^{7}$.

A ultrassonografiaé um exame eficaz, prático, sem sedação e de pequenogasto operacional. Permite detectarmassas e comorbidades na regiãopélvicaem crianças $^{1,4,6}$.A ultrassonografia de hidrohematometrocolpos detecta imagem de massa fusiforme na linha média da pelve, frequentemente anecogênica, de forma cística, com reforço acústico e com características heterogêneas ${ }^{6}$.

Desta forma, o objetivo deste relato foi descrever uma situaçãoclínica rara de hematocolpo com HI que deve ser consideradaquando do atendimento de crianças e adolescentes femininos com quadro de abdômen agudo. Tal ação evita exames desnecessários e condutas inapropriadas ejustifica a importância de anamnese e do exame físico precoce e minucioso.

\section{Relato do caso}

Paciente com idade de 11 anos, $41 \mathrm{~kg}$, internada no Hospital Universitário de Vassouras (HUV) após procurar o Pronto-Socorro (PS) queixando-se de dor em região do abdômen há 30 dias, do tipo cólica, de forte intensidade, de início em hipogástrio irradiando para a vagina. Referiu ter procurado o PS quatro vezes anteriormente sendo prescrito cefalexina, albendazol e dipirona, sem resposta. Negou febre, diarreia, alterações urinárias, tosse ou outros sintomas associados. Relatouausência de sexarca e menarca. Negou comorbidades.

Foram realizados no dia da internaçãoos exames complementares subsequentes: hematócrito de 37\%, hemoglobina 12,60 g/dL, hemácias de 4.590.000/ $\mathrm{mm}^{3}$, plaquetas de $332.000 / \mathrm{mm}^{3}$, leucócitos $7.010 / \mathrm{mm}^{3}$ (0-8/0-0-1-65/21-5), sódio de $147 \mathrm{mmol} / \mathrm{L}$, potássio de $4,9 \mathrm{mmol} / \mathrm{L}$, uréia de $25 \mathrm{mg} / \mathrm{dL}$, creatinina de $0,8 \mathrm{mg} / \mathrm{dL}$, TGO de 36U/L, TGP de 20U/L, fosfatase alcalina de 229U/L, gama-GT de 12U/L e proteína C reativa(PCR) sem alteração.

Manifestavafácies de dor, regular estado geral, posição antálgica, ativa, reativa, colaborativa, eupnéica, corada, hidratada, acianótica, anictérica e com boa perfusão capilar periférica. E temperatura axilar de $36,4^{\circ} \mathrm{C}$, frequência cardíaca de 113 batimentos por minuto (bpm), frequência respiratória de 18incursões respiratórias por minuto (irpm), glicemia capilar $101 \mathrm{mg} /$ dL, saturação de oxigênio de $98 \%$. Ao exame do tórax, apresentou murmúrio vesicular universalmente audível, sem ruídos adventícios, sem esforço respiratório, as bulhas cardíacas normofonéticas e taquicárdicas. O abdômen encontrava-se flácido, plano, peristáltico, timpânico, dor à palpação em região infra umbilical, com ausência de massas ou visceromegalias, sem sinais de irritação peritoneal. Evidenciou, ao exame do sistema genital externo, genitáliaparticularmente feminina com imperfuração himenial, abaulamentoefundo violáceo, e notou-seestágio de Tannerreferente a P3.

$\mathrm{O}$ exame rotineiro de urina não apresentouanormalidades. Realizou-se, também, rotina de abdômen agudo sem comprometimento do contorno cardíaco e diafragmático, presença de nível hidroaéreo à esquerda e pobreza de gases na ampola retal (Figura $1)$.

A ultrassonografia abdominal demonstrou massa isoecóica e a tomografia computadorizada de abdômen evidenciouimagem em região pélvica maciçahipodensa, homogênea, de lóculo único, limites regulares (Figura 2).

Durante o diagnóstico constatou-se hematocolpo secundário ao HI (Figura 3). A paciente, a partir disto, foisubmetida à himenotomiaimediata (Figura 4). A menor e o responsável que a acompanhava, consentiram quanto ao procedimento cirúrgico necessário, tendo recebido orientações sobre a acometimento em questão e a conduta a ser realizada. A responsável assinou o Termo de Consentimento Livre e Esclarecido (TCLE) e, em seguida, a cirurgia decorreu sem complicações. $\mathrm{No}^{\circ}{ }^{\circ}$ dia de pós-operatório (DPO),sangramento vaginal era brando, relatou dor à palpação abdominal profunda em hipogástrio, ausência deirritação peritoneal e boa evolução do quadro. Foi indicada alta hospitalar no terceiro DPO, com acompanhamento ambulatorial da ginecologia.

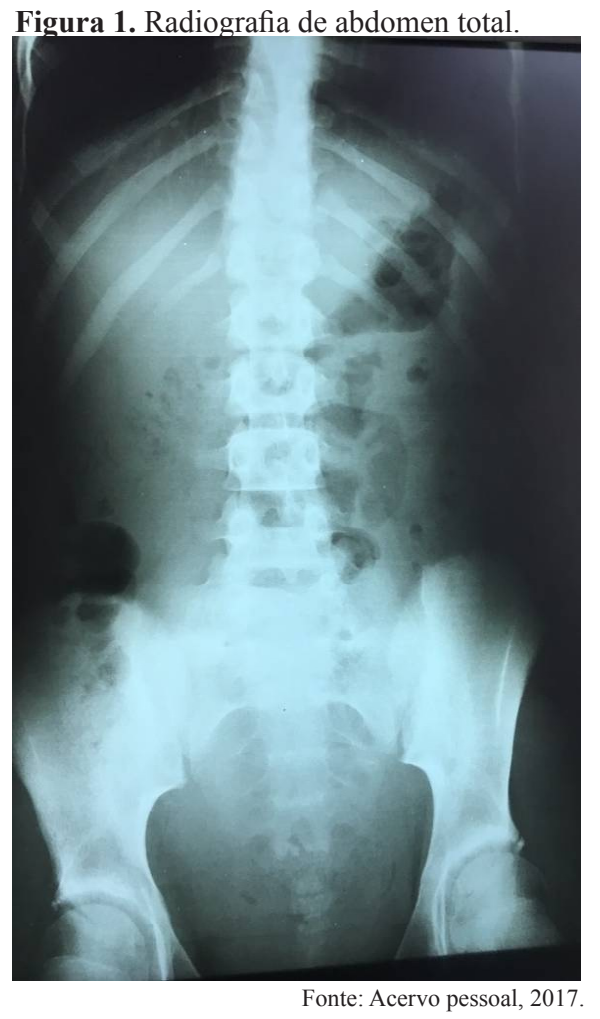


Figura 2. Tomografia computadorizada com contraste de abdômen.

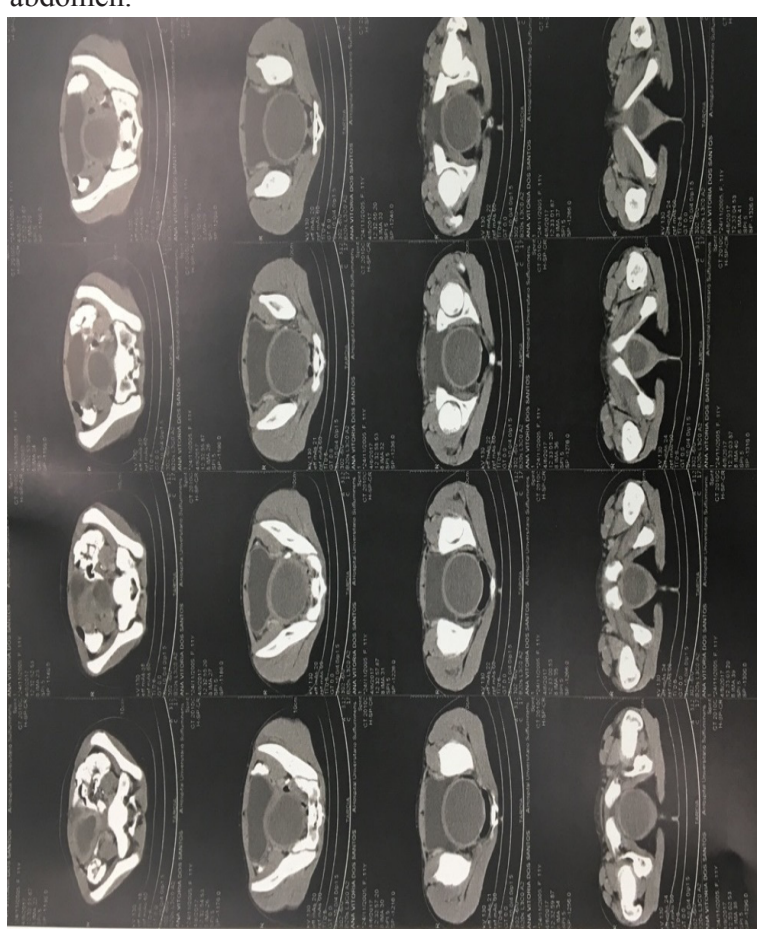

Fonte: Acervo pessoal, 2017

Figura 3. Hímen imperfurado mostrando imperfuração, abaulamento e profundidade violácea.

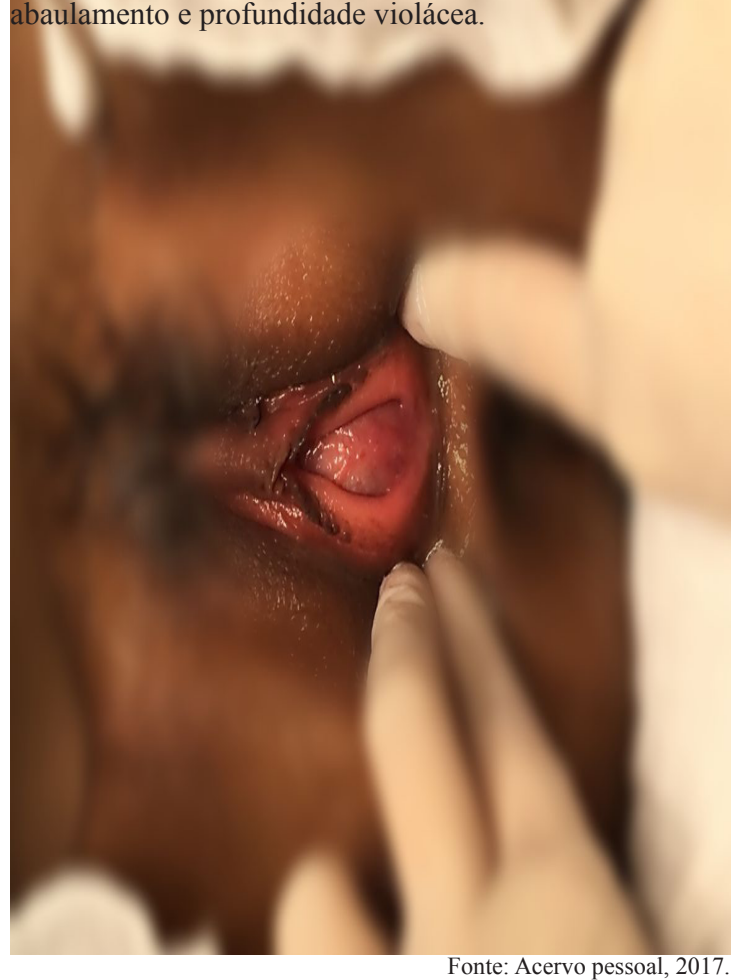

Figura 4. Himenotomia realizada.

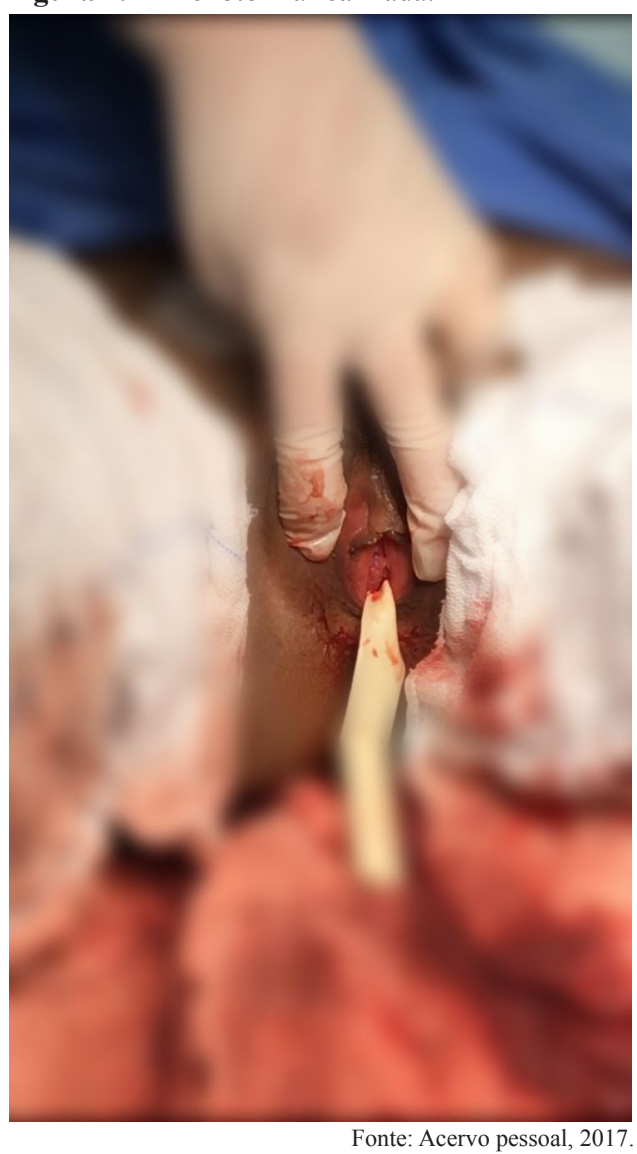

\section{Discussão}

Ohímen imperfurado ocorre em aproximadamente umaem cada duas milmulheres ${ }^{8}$.Em consequência da obstrução causada pela imperfuração himenial, ocorrem efeitos mecânicos sobre a uretra, bexiga, intestino e vasos sanguíneos pélvicos que podem resultar em dor abdominal, retenção urinária, constipação e edema de membros inferiores ${ }^{9}$.

No relato em questão, a divergência cerca do estádio de desenvolvimentopuberal e a inexistência de menarca,revelou o indício clínico mais importante.O diagnóstico precoce tornou-se, portanto, fundamental na prevenção de complicações como infecções, hidronefrose, insuficiência renal, endometriose e infertilidade ${ }^{8}$.

O diagnóstico é determinado à inspeção ao observar o abaulamento ou a membrana imperfurada no orifício vaginal, impossibilitando visualizar a cúpula. Esse fato é independente da faixa etária que se encontra, do período neonatal à adolescência. Destaca-se,assim, a inserção do exame genital na rotina das consultas em prol da saúde doneonato e infantil ${ }^{8}$.

O exame ultrassonográfico é auxiliar no diagnóstico,de fácil acesso, baixo custo eque não 
requer sedação, apesar da desvantagem de ser operadordependente ${ }^{1}$. Em função disto, tal exame foi solicitado para a paciente em questão.O principal diagnóstico diferencial foirealizado com fenestração himenial incompleta que, embora muitas vezes assintomática, necessita frequentemente de observação especializada dada a incapacidade na introdução de tampões, aplicação de tópicos vaginais ou dificuldade no coito $^{10}$.

\section{Conclusão}

HI é o fator congênito mais incidente em anormalidade uroginecológicade bloqueio ao fluxo em meninas e seu tratamento cirúrgico de escolha envolve uma incisão de himenotomia ${ }^{5}$. Portando, realiza-se tal técnica cirúrgica para correção com drenagem do sangue represadoedestaca-se pela completa melhora do quadroposteriormente, como no caso tratado. Conclui-se que oretardo no diagnóstico provocasintomas de abdômen agudo, acarretando em buscas poratendimentos em pronto-socorros? ${ }^{7}$. Entretanto, para que o desfecho não seja em momento inadequado, como o da paciente relatada, é necessária uma avaliação apropriada do sistema genital externo feminino ao exame físico, iniciando-se nas consultas neonatais. Como se trata de um procedimentosimples, são dispensáveis quaisquer exames ou condutas mais aprimoradas. A carência de conhecimento a respeito dessa patologiaatrasa o diagnóstico, gerando impassestal como executarlaparotomias dispensáveis e expansãoda morbidez.Assim,pode-se concluir quese deve inserir hematometrocolpos em diagnóstico diferencial ao deparar-se com massa em região da pelve e amenorréia ${ }^{4}$. Não hádados científicos efetivos sobre o momento ideal para identificar e tratar este tipo de caso, nem ao menos sobre a estratégia cirúrgica mais adequada. Deve-se orientar cuidadosamente os pais e o paciente sobre tal situação, principalmente para se evitar consequências psicossociais.

\section{Referências}

1. Khanna K, Sharma S, Gupta D. Hydrometrocolpos etiology and management: past beckons the present. PediatrSurgInt 2018; 34(3):249-26.

2. Rodriguez R, González J, Delgado R, Guedes A, Alvarado M, Castellano $\mathrm{M}$, et al.Fetal hydrometrocolpos and congenital imperforate hymen: Prenatal and postnatal imaging features. J Clin Ultrasound. 2018 March 23; 00:1-4.

3. Marzuillo P, Guarino S, Apicella A, La Manna A. Imperforate hymen. J Urology.2017; 43(1):102-103.

4. Paterson A, Gowdy S, Sweeney L. Hydrocolpos or Hematocolpos?. AJR.2012; 198(3):W324.

5. Basaran M, Usal D, Aydemir C. Hymen Sparing Surgery for Imperforate Hymen: Case Reports and Review of Literature. J PediatrAdolesc Gynecol. 2009; 22(4):61-4.

6. Rodrigues L, Lima R, Costa L, Batista R. Características das crianças nascidas com malformações congênitas no município de São Luís, Maranhão,
2002-2011. Epidemiol. Serv. Saúde [Internet]. 2014 June [cited 2018 July $16] ; 23(2): 295-304$.

7. Enes P, Brandao P, Ramoa P, Torgal A. Imperforate hymen: the importance of early diagnosis. Int $\mathrm{J}$ of Reproduction, Contraception, Obstetrics and Gynecology. 2017; 6(6):2628(3).

8. Lardenoije C, Aardenburg R, Mertens H. Imperforate hymen: a cause of abdominal pain in female adolescents. BMJ Case Rep. 2009; 2009:2-15.

9. Adam G, Sayal B, Suleuman G, Serdar GG. Hematocolpos causing severe urinary retention in an adolescent girl with imperforate hymen: an uncommon presentation. ArchGynecol Obstet. 2009; 280(3):461-3.

10. Liang CC, Chang SD, Soong YK. Long-term follow-up of women who underwent surgical correction for imperforate hymen. ArchGynecol Obstet. 2003; 269: 5-8. 